\title{
A Tract Reflection on Challenges in Research \& Development for New Product Development in the Industrial Sector of Pakistan
}

\author{
Arfan Shahzad \\ Othman Yeop Abdullah Graduate School of Business, University Utara Malaysia
}

Abdullah Kaid Al-Swidi (Corresponding author)

Othman Yeop Abdullah Graduate School of Business, University Utara Malaysia

Tel: 60-124-662-754 E-mail: swidi@uum.edu.my

Abd Ghani B Golamdin

School of Computing, College of Arts and Sciences, University Utara Malaysia

Received: November 13, 2012 Accepted: November 28, 2012

doi:10.5296/ber.v3i1.2677

URL: http://dx.doi.org/10.5296/ber.v3i1.2677

\begin{abstract}
New Product Development (NPD) is a strategic issue of successful business in the competitive era of the new global economy. Pakistan is relatively small, in the Asian region, yet a promising nation in the South East Asian region. Unfortunately, over the past few decades, the country's export performance has remained sluggish due to slower growth of NPD in her industrial sector. The present study conceptually examines the issue of challenges and remedial strategies involved in the context of R \& D in the process of NPD in Pakistani industries at-large. Indeed, textile industry is currently a major segment (46\%) of the Pakistani industrial sector. In general, the focus of the study is on NPD strategic criteria of the nation. The study discusses global and inward challenges and spells out the steps in formulating a new strategy towards NPD. Pakistan policy makers need to identify and focus on policies towards improvement of FDI inflows, industrial education, technology advancement, $\mathrm{R} \& \mathrm{D}$ budget, and establishing the industrial cluster among several other factors as building blocks of the NDP.
\end{abstract}

Keywords: Export, Industry, NPD, Strategy, R \& D, Pakistan 


\section{Introduction}

The process of developing a new product or service in the market involves a considerable attention to factors deployment and dealing with challenges faced by the industrial sector of a developing country. The major issue is pertaining to the concept generation, strategy development, organization of the processes, creating a marketing plan, commercializing the new product created and evaluating the whole process starting with the creation of the product and ending with its actual realization by customers. In this context, there has been a well-established cooperation and coordination, by several studies in the literature, between the research and development (R\&D) and marketing efforts. If these efforts have been well-aligned, they will result in a high NPD success rate and thus in high firm competitiveness (Atuahene-Gima \& Evangelista, 2000). By and large, R\&D strategy with effective marketing plans can substantiate the company's capabilities in meeting the customers' needs and exceeding their expectations (Ruekert, \& Bonner, 2001). Indeed, R\&D and marketing association bound to play a dynamic role in the business positioning of envisaged NPD. The NPD process comprises a number of stages in which $R \& D$ and marketing collaboration constitute a critical step. R\&D and marketing personnel, however, hold a different perspective on the NPD process. For them, the improvement strategy and environmental care also cause a denting effect on NPD performance in reality.

This paper specifically focused on the issues of new product development in Pakistan as a promising nation in the south east region. Being a land of rich natural resources Pakistan is a growing developing country with great potential. Pakistan, as a country, resulted from the partition of the Indian subcontinent on 14 August 1947. Pakistan is inhabited by millions of people with varied skills and talents. Geographically, the land area Pakistan is about 796,096 square $\mathrm{km}$. With many other attractive tropical features, Pakistan has high mountains in the north and coastal plains in the southern part of the country. Due to the natural resources and other business environment-related factors, Pakistan has been an attractive country for many foreign investors.

Data in Table 1 highlights the trend of Pakistan's foreign trade and GDP growth rate in recent years.

Nonetheless, Pakistan is recognized as an upcoming province Muslim nation aspiring for growth and development in the current decade (2011 onwards) under the leadership of Prime Minister (PM) Yousf Raza Gilani. At the launching ceremony of the Infrastructure Development of the Pakistan Textile at Port Qasim Industrial area, the Prime Minister pointed out the significant contribution of the Textile industry towards the growth of Pakistan economy. Virtually, Pakistan's textile industry is relatively large in the Industrial sector and its total export was valued at around 9.6 billion US dollars in the year 2010. In fact, the textile industry contributed roughly 8.5 percent to the overall GDP of the country in 2010 (khan \& khan, 2010; khan, 2012). In Asia, Pakistan is the eighth largest exporter of textile goods and generating employment to 38 percent of the total work force in the country. In fact, the textile industry of Pakistan currently encountering insurmountable challenges due to the raising competition in the world economy. In the global situation today, thus, all Pakistan Textile Mills Association 
(APTMA) inevitably needs to enhance the quality of its new products. It was argued by the APTMA that there are some other factors including the high interest rates and the input cost, unsupportive government policies, and fluctuating energy supplies obstruct their global competitiveness.

Table 1. Pakistan imports, exports and GDP since 2000 to 2010

\begin{tabular}{|c|c|c|c|}
\hline Year & Import & Export & $\begin{array}{c}\text { GDP Growth } \\
\text { Rate }\end{array}$ \\
\hline 2001 & 9201.6 & 10728.9 & 3.11 \\
2002 & 9134.6 & 10339.5 & 4.73 \\
2003 & 11160.2 & 12220.3 & 7.48 \\
2004 & 12313.3 & 15591.8 & 8.96 \\
2005 & 14391.1 & 20598.1 & 5.82 \\
2006 & 16451.2 & 28580.9 & 6.81 \\
2007 & 16976.2 & 30539.7 & 3.68 \\
2008 & 19052.3 & 39965.5 & 1.21 \\
2009 & 17688.0 & 34822.1 & 4.09 \\
2010 & 19290.0 & 34710.0 & 3.76 \\
\hline
\end{tabular}

Source: UNCTAD, 2011

Indeed, under the fast developing global market, rapid changes in consumer tastes, and modern technology and intensified competition must be attentively exploited in initiating a steady stream of new product development. In the process of various approaches, a prominent one is the green investment i.e. the acquisition of buying a whole company, or collaborative investment, to produce new else's products in the global and local arena. The company's own new research and development department should focus grossly on innovation towards greater competitiveness.

\section{Motivation of the Study}

In business parlance, new product development (NPD) refers to the entire development of creating a new product in serving the market. In NPD processes, there are two innovative modes. The first one is related to the idea generation that matters the most and the product design. The second is pertaining to the market positioning and market penetration based on the new product. This indicates the importance of market research and marketing analysis in the NPD processes. By and large, companies typically perceive the phenomenon of new product development at the first phase of operation in the generation and commercialization of the product to sustain their market share and business position.

In Pakistan, however, in the process of NPD many problems are caused by the attention of the industry in the Punjab and Sind along with other market segments and centers in the country. The lack of R \&D in the Pakistan industrial sector has been one of the main reasons behind the low quality of products in comparison to other Asian countries. Besides, the shortfall of appropriate $R \& D$ has led to such a dismal state. Industries in Pakistan have above put further blamed cartels, especially in the pesticide sector, for hindering the appropriate growth and 
application of R\&D (Khan \& khan, 2010). Pakistani made products mostly deal with local needs and rarely catering to the international market standard.

In the global economic arena, quality of products is prejudiced by marketing appeals and judged by the country brand effect. Indeed, the outcome of positive country brand image largely is influenced by varying socio demographics features and impact of national culture (Lee \& Tai, 2006). Of course, it is observed that the attitudes of buyer towards the country of origin and corporate image exerted a great deal of appeal on their perceptions of product merits and purchasing behavior (Liu \& Johnson, 2005). As Liu and Johnson study pointed out the country of origin effects tend to occur repeatedly and contribute to product evaluations favorably without consumers' acknowledgement or attentive intention. The Pakistan Industrial sector is largely confined to SMEs. However, from the innovation point of view, the SMEs in Pakistan have a minimal innovative contribution based on NPD strategies. This can be attributed to several regulatory burdens on the private sector, the lack of accessible capital and the insufficient supply of highly qualified human capital to enhance the NPD capabilities of the SMEs.

\section{Literature Review}

In view of the dearth of studies about Pakistan on the issue of NPD, we have resorted to examine a few selected developing countries to capture some clue for discussion. New Product Development (NPD) process research is governed by new environmental context and a new business model in the modern era. Among recently emerging fast developing countries, Taiwan's IT industry has achieved a very remarkable performance during the last two decades. Taiwan, however, can be a good model to be followed by other countries that are struggling to achieve a good position in the Marke. In other words, Taiwan has a good experience that can benefit other emerging countries to transform their business from making low-value products to manufacturing high-technology products (Louis et al., 2003).

According to Ho (2006), advance globalization leads to a really competitive market environment referring to five major aspects, namely, decision making, market intelligence, culture-based behavior, strategic focus and customers. A business firm must develop unique and successful new products for business sustainability and growth in global markets. New product position environments have drastically changed in the new millennium. The success of new product in the global arena largely attributed to superior quality, low cost, and product differentiation. However, a risk involved in new product commercialization stage usually tends to be much higher than threat of new entry in the global competitive markets.

Studies such as the one conducted by wand et al. (2002) and Geuens et al. (2002) have identified two dimensions in the NPD strategy: scale of investment and time of entry on R\&D and marketing issues. Based on that, the researchers have developed a framework and suggested a measure of the level of R \& D for NPD marketing. In this manner, the literature on the $\mathrm{R} \& \mathrm{D}$ marketing interface has greatly highlighted the interaction between the $\mathrm{R} \& \mathrm{D}$ strategies and the success of NPD initiatives.

It has been pinpointed that the process of NDP involves an integral associations between the 
product quality of mark advantage, image and real product quality. Lee et al's (2002) study on Kazakhstan provides some more insights into the factors that influence standardization of marketing promotional elements of MNCs in Kazakhstan. The finding of this study, however, may have limited in literature review impact since Kazakhstan does not feature the same characteristics of other newly emerging markets in the global arena. For a developing nation, however, in the NPD processes all the decisions related to marketing mix should be made with the view of the product market life cycle (Hart et al., 2000).

Rosier et al. (2008) narrated challenges confronting the senior advertising team in B2B firm regarding a major issue as how to ensure that the marketing strategies that are developed by the team are implemented successfully. It is heartening to note that an increasing number of Pakistani owned foreign companies have tended to establish setting up development center operations in Pakistan. On the domestic market fronts as well, there is a growing possibility of large opening up on a large scale and transformation of traditional conservative segments of the economy with attentive focus on R\&D towards NPD.

According to Yuksel (2004), an understanding of domestic and international markets in delivering service quality of product caters to the potential demand of these markets are the need of the hour for retail and commercial enterprises in a dynamic economy. It has been observed that the rising world economy, several organizations have fabricated their web for furnishing information about their products or services. Market uncertainty phenomenon and corresponding risks can be measured based on how complex the market, the dynamic changes and volatility of the market. As Gok and Hacioglu (2009) have narrated, environmental distance has its profound impact on the political, cultural and economic significance of cross functional international economic relations and cooperation so also it can moderate the relationship between R\&D marketing cooperation and NPD performance. Also, when competition is high, $R \& D$ and marketing concerned individuals must visualize step towards stronger collaboration so as to win in the competitive games.

\section{Global and Inward Challenges for Pakistan Industry}

Over the last many decades, the Pakistani industrial sector has been facing a myriad of challenges pertaining to growth and NDP dynamism. A few of them is briefly examined as in the following.

\subsection{Increasing Cost of Production}

The cost of production is a basic issue due to many reasons such as increasing interest rate, double digit inflation rate, and diminishing the external value of Pakistani rupee. The rising cost of production continually implies an acute problem for new product development and corresponding $\mathrm{R} \& \mathrm{D}$. The global recession that affected greatly the global industry is not the only cause for concern in a developing economy such as Pakistan. The high cost of manufacturing resulting from a continual rise in the energy costs has been the major concern for the industry in a developing economy in the global setting. As a matter of fact, the significant depreciation of Pakistani rupee external value against the US dollar during the last four years 2007 and a half onwards has caused a tremendous rise in the cost of imported inputs, 
thus, adversely affecting the process of NPD.

\subsection{State of Research and development in the Industry}

Absence of adequate research \& development (R\&D) in the industrial sector of Pakistan has resulted in poor quality of the product in comparison to competitor's products in the rest of the world. It is clear that the Pakistan Industry is wadding through an uncertain and risky business environment. Through R\&D, and TAAFC technological acquisition, adoption and further improvement Pakistani enterprises can hope to come out with NPD of large appeal. It is possible only through practical application of knowledge and skills management by the establishment, zeal for improvement and extension of facilities towards designing and improvements of envisaged product.

\subsection{Lack of Modern Equipment}

Most of the Pakistani enterprises have adopted obsolete equipment and machineries. The incapability to timely update in the tools and machinery has adversely affected Pakistani industry's global competitiveness. So also, due to obsolete technology the cost of production is much higher in Pakistan as compared to Asian counterparts such as Bangladesh, China, India and Sri Lanka. It follows that special focus is required to adopt modern technology in the process towards NPD in Pakistan.

\subsection{Electricity Crisis}

A continues phenomenon of power shortage is the main problem faced by the Pakistan industrial sector. As a matter of fact, power shortage caused a reduction in production capacity of various sub-sectors up to 30 percent. Gas load-shedding remarks a continuous phenomenon in Punjab and NWFP unbearable despite a significant increase in heat during summer. A spokesman for the all Pakistan Textile Mills Association (APTMA) claimed that due to power units 60 to 70 per cent of the industry had been affected and was unable to accept export orders coming in from around the globe. Some of industry units have built their own energy generating plants to cut costs (these units run on gas), their small unit production, however, depends solely entirely on the electricity supply of WAPDA. By and large, the Pakistan Industry sector has suffered heavy financial losses during 2008 to 2012, owing to of the inconsistent electricity supply management in the country.

\subsection{Raw Material Prices}

Input-cost is a burning issue of Pakistan due to the high cost of raw material. In Pakistan, the prices of raw material in the industry change rapidly. This increase in the price of raw materials tends to cause high the cost of finished product. In recent years, the increase of the prices of the raw material, as inputs to the industry, has gone up rapidly due to double digit inflation and instable internal eco-political environment of Pakistan. The major issues faced by most of the industrial enterprises in Pakistan include the difficulty in getting good quality raw materials, categorizing of the raw materials, improving the production both quality and quantity wise in the process of NPD, time and again. 


\subsection{Low Labor Productivity}

Pakistani labors are unskilled and untrained. Labor productivity as such is comparatively low in Pakistan. New product development, apparently, needs highly productive labor. Pakistani policy makers should prepare an agenda of labor training, education and skill development under the Human Resource Development programs.

\subsection{The Effect of Global Recession on Pakistan Industry}

In recent years, Pakistan has witnessed a declining export trend (see Table 1). The export orders have specifically receded due to unpredictable low and other conditions of Pakistan in the wake of political instability. Under a dismal economic situation, as such here is no incentive and less hope for the NPD.

\section{Recommendations}

For a concrete improvement in the future course of direction, to be considered by the policy makers, we may spell out a new strategy toward NPD of Pakistani Industrial sector. The new strategy for economic growth for Pakistan industry should not, as today, focus merely on rising exports and liberalizing global trade, but should foster internal demand stronger through job creation and pay likes and redistribution of incomes for improving the incomes and spending's of the poorer strata of the people. This would create a market driven incentives for NPD in the country. In the country, major industries should be encouraged by the policy makers through plans and projects to establish their own R\&D facilities and to enhance the cooperation and relationships with universities, consulting centers and $R \& D$ institutions. In addition to that, the government should have a crucial role in bringing together business entities and expertise institutions. This could e done including some experienced individuals from industry in relevant governing bodies of Universities to contribute in bridging the gap between the business and research. Policy makers should initiate and encourage exchange of manpower among Government, universities, $R \& D$ institutions and industries. Contractual research by R\&D institutions through lavish grants should be encouraged by the Government.

For Technology Up-gradation, thus, the government should enhance R\&D budget, sanction large funds for quality technical education, and encourage innovation-based projects in the universities and R\&D institutions. Major focus should be on New R \&D for industry through inventions and competitive innovation.

It this regards, National Innovation System and policy framework should be evolved in such a way that would ensure optimal use of a country's economic and business resources. Consultative workshops on National Innovation System should be functioning with zeal and regular it's at the national level and case studies undertaken for reflecting successes and failures to promote rapid learning of good innovation practices. Instituting the development of human resources at various entailing high priority to enable the effective structuring and implementation of a National Innovation System.

By and large, projects implemented by $R \& D$ institutions should be recognized in economic importance and business propositions for NPD. Industry should be involved in the 
development of such $\mathrm{R} \& \mathrm{D}$ projects and provide sponsorship for encouragement on a wider scale.

It may be emphasized that Pakistan should enhance innovation capabilities in the domain of industrial technologies and transform traditional practices through the effective employment of innovative technological advancements, such as, improvement in productivity, introduction the latest machinery, removes the energy crisis, technological innovation, Exploration of new markets territories, Improve the education in Industry field and technology, cost effectiveness of developing new products, seeking global integration with penetration into the world market, transportation enhancement, Safety for foreign investors and their corporation, Build the infrastructure into the country same like as the developed country.

Increase the industrial zones in county for joint R\&D programs in facilitating the NPD. Involve industrial organization and administration to acknowledge the significance of knowledge worker. Knower comes first then the knowledge. Pakistan policy makers and the administration should study china and other country's development polices and churns ideas to be adopted with suitable modifications.

\section{Conclusion}

The study discussed global and inward challenges and spell out the steps in formulating a new strategy toward NPD. Pakistan economy and industry are experiencing a declining business environment. Moreover, the global downturn which has hit the global prospects for Pakistan's for an industry that is the main cause of concern in the process of NPD. Pakistan industry is lacking in growth of research \& development ( $\mathrm{R} \& \mathrm{D})$. The production capability is bottom low due to obsolete machinery \& technology in use. Besides, serious internal issues also affected Pakistan entire industrial sector very badly. It has been widely acknowledged that the high cost of production due to the rising costs of the energy fuel and electric power has been the major issues in the country. To boost the growth of NPD Pakistan in pragmatic industrial policy, removal of conflicts between environmental issues and facilitating economic growth through industrial growth in the high pin of the policy matters. Pakistan policy makers need to identify and focus on policies towards improvement in FDI, industrial education, technology advancement, and R \&D budget, establishment of the industrial cluster among several other factors as building blocks of the NDP in the country.

\section{References}

All Pakistan Textile Mills Association (APTMA) (Various Issues) Annual Report.

Atuahene-Gima, K., \& Felicitas, E. (2000). Cross-functional influence in new product development: An exploratory study of R\&D and marketing perspectives. Management Science, 46(10), 1269-1284. http://dx.doi.org/10.1287/mnsc.46.10.1269.12273

Baker, W. (2007) Branding of post-purchase ancillary products and services: An application in the mobile communications industry. European Journal of Marketing, 44(5), 547-566. http://dx.doi.org/10.1108/03090561011032261

Cheung, K., Kwok, J., Law, M., \& Tsui, K. (2003). Mining customer product ratings for 
personalized marketing. Decision Support Systems, 35(2), 231-243. http://dx.doi.org/10.1016/S0167-9236(02)00108-2

Geuens, M., De Pelsmacker, P., \& Faseur, T. (2010). Emotional advertising: Revisiting the role of product category. Journal of Business Research 64.4 (2010), 418-426. http://dx.doi.org/10.1016/j.jbusres.2010.03.001

Gök, O., \& Hacioglu, G. The organizational roles of marketing and marketing managers. Marketing Intelligence $\quad \& \quad$ Planning, 291-309. http://dx.doi.org/10.1108/02634501011041435

Hart, S., \& Tzokas, N. (2000). New product launch "mix" in growth and mature product markets. Benchmarking: An International Journal, 7(5), 389-405. http://dx.doi.org/10.1108/14635770010359874

Ho, Y., Lee, G., \& Chao, Y. (2006). A Conceptual Framework of Organizational Integration and Product Launch Activities Proficiency on Market Success. Paper presented at the Management of Innovation and Technology, 2006 IEEE International Conference on. http://dx.doi.org/10.1109/ICMIT.2006.262279

Hofstede, G. H. (1980). Culture's consequences: International differences in work related value. Beverly Hills, CA: Sage Publications. Journal of Advertising, 34(1), 87-97.

Khan, Aftab A. Khan, \& Mehreen (2010). Pakistan Textile Industry Facing New Challenges. Research Journal of International Studies, 14.

Khan, W. (2012). Impact of Capital Structure on Stock Returns:'A Case of Pakistani Textile Industry'. Available at SSRN 2063554.

Lee, J. W., Tai, S. W., \& Low, P. (2007), "Impact of cross-cultural dissimilarities on human resource management in transitional economies. ICFAI Journal of Organizational Behavior, 6(2), 34-45.

Lee, J., \& Tai, S. (2009). Determinants of product quality perceptions and their application to marketing standardisation: The case of the automobile in Kazakhstan. International Journal of Emerging Markets, 4(2), 119-136. http://dx.doi.org/10.1108/17468800910945765

Liu, S. S., \& K. F. Johnson(2005).The Automatic Country-of-Origin Effects on Brand $\begin{array}{llll}\text { Judgments. } \quad \text { Journal } & \text { of } & \text { 8dvertising, }\end{array}$ http://dx.doi.org/10.1080/00913367.2005.10639183

Lu, L., \& Yang, C. (2004). The R\&D and marketing cooperation across new product development stages: An empirical study of Taiwan's IT industry. Industrial marketing management, 33(7), 593-605. http://dx.doi.org/10.1016/j.indmarman.2003.11.002

Rosier, E., Morgan, R., \& Cadogan, J. (2010). Marketing strategy and the efficacy of procedural justice: The mid-level marketing manager in industrial service firms. Industrial Marketing Management, 39(3), 450-459. http://dx.doi.org/10.1016/j.indmarman.2008.10.002

Ruekert, R. W., \& Walker Jr., O. C. (1987). Marketing interaction with winners from losers? 


\section{Macrothink}

Business and Economic Research

ISSN 2162-4860 2013, Vol. 3, No. 1

Journal of Product Innovation Management, 4(3), 169- 187.

Wang, Q., \& Montaguti, E. (2002). The R\&D-marketing interface and new product entry

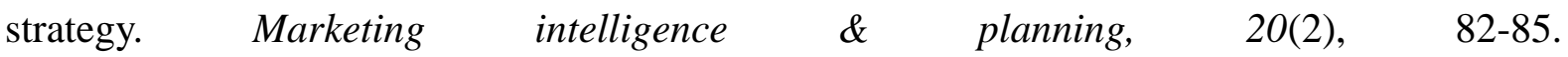
http://dx.doi.org/10.1108/02634500210418491

Yuksel, A. (2004). Shopping experience evaluation: a case of domestic and international visitors.

Tourism

Management, $25(6)$,

751-759.

http://dx.doi.org/10.1016/j.tourman.2003.09.012

\section{Copyright Disclaimer}

Copyright reserved by the author(s).

This article is an open-access article distributed under the terms and conditions of the Creative Commons Attribution license (http://creativecommons.org/licenses/by/3.0/). 